\title{
En busca del ideal de naturalidad estilística a partir de las fórmulas de inicio de turno en el diálogo (s. XVI)*
}

\author{
Finding the ideal of natural style from formulae at the beginning \\ of dialogical turns $\left(16^{\text {th }}\right.$ century)
}

Santiago del Rey Quesada Fundación Alexander von Humboldt / Ludwig-Maximilians-Universität Múnich sdelrey@romanistik.uni-muenchen.de

\begin{abstract}
RESUMEN: Atendiendo a diversas fórmulas de inicio de turno conversacional que aparecen profusamente en los Colloquia familiaria de Erasmo y sus traducciones castellanas, se analiza en este artículo cómo dichas fórmulas se convierten en una estrategia discursiva característica de la tradición del diálogo renacentista y barroco. Su rutinización en este tipo de textos puede interpretarse como una manifestación del ideal de naturalidad estilística en boga a partir de la primera mitad del siglo XVI en la literatura castellana.
\end{abstract}

Palabras clave: Diálogo, estilo, mimesis conversacional, Erasmo, Siglo de Oro.

ABSTRACT: Regarding some formulae at the beginning of the dialogical turns that profusely appear at Erasmus's Colloquia familiaria and its Castillian translations, we study in this paper how these formulae become a discursive strategy which characterizes the dialogical tradition at the Renaissance and Baroque. Its routinization in texts of this kind may be interpreted as an expression of the ideal of natural style that succeeded since the first half of the $16^{\text {th }}$ century in Castilian literature.

Keywords: Dialogue, style, conversational mimesis, Erasmus, Spanish Golden Age.

* Trabajo enmarcado en el proyecto "Tradiciones discursivas, tradiciones idiomáticas y unidades de análisis del discurso en la historia del español moderno" (FFI2014-51826-P). 


\section{INTRODUCCIÓN}

La famosa máxima de Valdés, equiparada a la propia ideología linguiística del autor, "el estilo que tengo me es natural, y sin afetación ninguna escrivo como hablo", ha dado pie a diversas interpretaciones sobre el ideal estilístico del escritor conquense y de otros muchos autores a partir del primer tercio del siglo XVI. Más recientemente, algunos hispanistas han considerado conveniente estudiar tal afirmación en el contexto de las investigaciones sobre oralidad y escrituralidad de acuerdo con el modelo variacionista propuesto por Koch y Oesterreicher (2007 [1990]). Efectivamente, las implicaciones teóricas del precepto valdesiano guardan relación con el problema de lo oral y lo escrito que, de acuerdo con los presupuestos de los autores anteriormente citados, puede representarse mediante un esquema en el que existirían dos polos, el de la inmediatez y el de la distancia comunicativas, entre los que se establece un continuum concepcional.

A su vez, como Bustos (2011), Oesterreicher (1996), Gauger (1996 y 2004) y Rivarola (1998) observan, la afirmación del "escribo como hablo" no puede entenderse aislada del contexto cultural en el que aparece, de las corrientes retóricas vigentes a partir del Humanismo y de la realidad variacional de los textos que cristaliza en diversas tradiciones discursivas (TD). Creo que aún no se ha insistido lo suficiente en la importancia que, en la concepción del estilo imperante en este primer tercio del siglo XVI, tuvieron los escritos de Erasmo de Rotterdam en España, algo que desde el punto de vista ideológico ya subrayó con fundamentadas razones Marcel Bataillon (2007 [1966]) y que, respecto a su influencia en las teorías del estilo y de la retórica también ha sido puesto de manifiesto, entre otros, por López Grigera (1986).

Más concretamente, a través de un conjunto nutrido de ejemplos, pretendo hacer balance aquí de cómo los Coloquios de Erasmo, obra de gran difusión en toda la Europa renacentista, y, en particular, las traducciones castellanas de estas —escritas, la mayoría, entre 1527 y 1529- contribuyeron al desarrollo y especialización del discurso dialógico en España. Parto de la hipótesis de que se trata de una serie de textos clave para entender el "salto cualitativo" que, según Bustos (2007: 220-221) se produce entre la Edad Media y el Renacimiento en cuanto a los resultados de textualización de la oralidad que consiguen diferentes autores de una y otra época. Con el fin de constatar esta hipótesis de trabajo, pretendo analizar diversas fórmulas de inicio conversacional en los Colloquia y sus traducciones; a partir de aquí, he considerado oportuno realizar búsquedas en el CORDE para constatar o desestimar la extensión de las mismas.

En este sentido, no será difícil percibir cómo la estela del erasmismo, tan fecunda en autores como Alfonso de Valdés, Cervantes o Quevedo, dejó también semilla en el ideal estilístico que propugna Juan de Valdés y en qué medi- 
da su manera de escribir contribuyó asimismo a la gestación de una nueva forma de construir discursivamente los textos, particularmente aquellos en los que se produce lo que ha dado en llamarse una mimesis de la oralidad.

En definitiva, del mismo modo que se ha considerado fundamental la interpretación del precepto valdesiano de "escribo como hablo" como una afirmación que presupone el cultivo, de acuerdo con el ideal humanista, del propio hablar (cfr. Gauger, 1996) o como un ideal de estilo que requiere, inversamente, el habla como reflejo de una forma natural de escritura (cfr. Bustos, 2011), es necesario destacar la importancia de Erasmo de Rotterdam, ya intuida y apuntada por los estudiosos que han abordado esta cuestión (cfr. por ejemplo, Cano Aguilar, 1991: 50), en la conformación y éxito de esta máxima estilística, con el propósito paralelo de destacar la figura de Erasmo no solo como autor literario de gran influencia en la historia de las ideas europea, sino también como maestro de naturalidad estilística al que siguieron muchos otros escritores en los siglos posteriores y como inspiración fáctica del precepto que habría que discutir con más detenimiento a la luz de la obra del sabio holandés, quien en una de sus epístolas escribe: "[y]o no estoy de acuerdo con los que, totalmente despreocupados de los preceptos, buscan el arte de hablar en las autoridades, ni con los que, abandonados a los preceptos, no se detienen en leer a las autoridades. Los preceptos quiero que sean pocos, pero los mejores; lo que resta, considero que se debe buscar en los mejores escritores o en la conversación de los que hablan como aquellos escribieron" (OEDER, núm. 1115, lín. 28-34, p. 290; traducción mía).

\section{FORTUNA DE LAS FÓRMULAS DE INICIO DE TURNO CONVERSACIONAL DOCU- MENTADAS EN LOS COLLOQUIA Y SUS TRADUCCIONES}

Entre los numerosos rasgos típicamente dialógicos que podrían aducirse al respecto de la máxima de naturalidad (cfr. del Rey, 2015a), basta fijarse en ciertas fórmulas que se encuentran a principio de turno de las intervenciones de los personajes para rastrear de qué manera las formulae más utilizadas por Erasmo en este contexto constituyen un elemento reiterativo que caracteriza una determinada tradición discursiva ${ }^{1}$. Por supuesto, también es posible encontrar este tipo de inicios conversacionales en los diálogos insertos en obras de carácter narrativo. A continuación mencionaré algunas de las fórmulas más importantes de esta clase que se encuentran en los Colloquia. Para obtener resultados

\footnotetext{
${ }^{1}$ Sobre el concepto de TD pueden verse, entre otros muchos, los trabajos de Schlieben-Lange (1983), Koch (1993 y 1997) y Oesterreicher (1997 y 1998), Kabatek (2001 y 2005), Aschenberg (2003), López Serena (2007) y Vincis y Miotto (2016).
} 
más seguros en este sentido, he reunido un corpus de coloquios erasmianos en latín, concretamente 42 (apud DERFC y Halkin, Bierlaire y Hoven, 1972). He seleccionado las formulae de inicio de turno conversacional más frecuentes en Erasmo y, a continuación, he realizado una búsqueda en el CORDE con los segmentos que, según he podido comprobar, funcionan más habitualmente en la prosa castellana como traducciones de esas fórmulas, según se desprende de mi experiencia con las versiones mismas de los Coloquios y con otros diálogos renacentistas.

Determinados inicios de turno usados por Erasmo, - aunque por supuesto, en mayor o menor medida, también se pueden encontrar en los diálogos latinos preclásicos (sobre todo, en la comedia ${ }^{2}$ ), clásicos y posclásicos-, son presentados por el mismo autor holandés como formulae en las primeras versiones de sus Colloquia. Creo que, en muchos casos, estas se convierten a lo largo del Renacimiento en elementos caracterizadores de la tradición dialógica. Un análisis cuantitativamente exhaustivo ${ }^{3}$, como el que proporcionaré a continuación, contribuye a la constatación de esta hipótesis ${ }^{4}$. Hay que tener en cuenta, asimismo, cuántas de estas fórmulas se pueden localizar antes del

\footnotetext{
${ }^{2}$ No debemos, en efecto, subestimar el papel desempeñado por las Comedias de Terencio en el proceso de difusión y consagración de estas fórmulas. Lamentablemente el CORDE no recoge las traducciones de sus obras, muy cercanas cronológicamente a las traducciones de los Coloquios erasmianos, ni la traducción del Anfitrio de López de Villalobos (1517), en la que aparecen también algunas de las fórmulas analizadas, sin duda un precedente digno de atención en el que, por cuestiones de espacio, no podemos por desgracia detenernos. Sobre las influencias latinas en Erasmo y sus consecuencias en el estilo, cfr. Tunberg (2004: 160-161)

${ }^{3}$ La exhaustividad de la investigación aquí está limitada por la naturaleza irregular del corpus electrónico CORDE, como todos los historiadores de la lengua comprenden.

${ }^{4}$ No conviene olvidar, por lo demás, el peso que las traducciones italianas tienen en esta época, algo que, desde una perspectiva no estrictamente lingüística han apuntado diversos autores como Russell (1985), Alvar (1990) y Serés (1997). Asimismo, el hecho de que algunas fórmulas no sean inéditas en el Renacimiento hace que nos planteemos la pregunta de hasta qué punto las fórmulas que aparecen en el diálogo de entre 1520 y 1700 (período que identificaremos con las siglas SO) no son adaptaciones o desarrollos de ciertos elementos de inicio de turno en la época precedente (sobre todo en el siglo XV y principios del XVI), favorecidos un poco más tarde por el frecuente uso que de ellos o de otros similares se hace en la prosa erasmiana. Es interesante en este sentido ver cómo en el caso de fórmulas como Maravillado/a estoy/soy no es esporádica su presencia en los diálogos de la novela de caballerías como el Palmerín de Olivia o el Primaleón. Con todo, defiendo que la influencia de Erasmo en lo que se refiere a la utilización de la mayoría de estas fórmulas en el diálogo renacentista, más allá de influencia literaria extranjera o continuación de elementos de TD medievales asimilables a la del diálogo renacentista, es decisiva, sobre todo en la primera mitad del siglo XVI, período de SO donde puede localizarse el mayor número de fórmulas que estudio en las siguientes páginas. Hay que destacar, en fin, que es España el país europeo en el que las traducciones de los Coloquios adquieren mayor difusión gracias al clima de libertad ideológica que cunde durante el reinado de Carlos V, época en la que, además, a la par de estas traducciones o inmediatamente después, van apareciendo los diálogos renacentistas más reconocidos.
} 
período que considero el de principal influencia erasmiana en España, es decir, de 1520 a 1700 (lo llamaré período SO). Entiendo que el peso adquirido en el discurso dialógico por estas fórmulas es relevante cuando más de la mitad del total de las ocurrencias de estas se localiza en este lapso temporal. Tengo en cuenta también que no más de la mitad de las ocurrencias contabilizadas entre 1520 y 1700 se haya dado en época medieval ni en los 19 años previos a 1520 (lo llamaré período ASO), pues tal hecho indicaría que la presencia de esas fórmulas puede deberse a una tradición secular en la literatura castellana y no principalmente revitalizada por Erasmo. Con todo, merece ser notado cuándo las ocurrencias de ASO datan de los siglos XIII y XIV o XV y XVI, pues la especialización del discurso dialógico, aunque, a mi parecer, impulsada por la prosa erasmiana, comienza su recorrido en el diálogo celestinesco. Me referiré al período posterior a SO, es decir, desde 1701 a 1975, mediante las siglas PSO $^{5}$.

2.1. Muchas de estas fórmulas están constituidas por verbos de lengua en latín y otros performativos. La forma de futuro Dicam ${ }^{6}$ suele iniciar el turno de un personaje que se presta a responder una pregunta propuesta por el interlocutor, focalizando catafóricamente el enunciado que sigue a esta fórmula enfática presentativa, expresión de una gran seguridad en los argumentos por parte del

\footnotetext{
${ }^{5}$ Sin duda los datos cuantitativos que proporciona un corpus electrónico como este (cfr. n. 3) son irregulares, pero en cualquier caso permiten comprobar si una fórmula en cuestión aparece o no antes del período SO. Evidentemente, una mayor difusión en otras épocas estaría hablando de una mayor asimilación de la fórmula ya en autores y/o tradiciones discursivas precedentes, especialmente si tenemos en cuenta que la proporción de número de palabras por siglo en CORDE no es muy equilibrada. Con todo, que algunas de estas fórmulas se den en la Edad Media no contradice, como veremos, la hipótesis de que la literatura erasmiana posterior fuera un elemento catalizador de ellas en la prosa áurea.

${ }^{6}$ La mayúscula es importante porque es un indicio tipográfico fundamental que marca inicio de turno o, en contextos monológicos, de enunciado, de acuerdo con las pautas de edición más extendidas ya desde los inicios de la imprenta, aunque en el Siglo de Oro y, en general, hasta el comienzo de las reformas ortográficas de la Academia, ello no siempre fuera un dato decisivo en este sentido. Sí es importante destacar la utilidad del empleo de la mayúscula en las búsquedas del CORDE, pues aquí sí se puede realizar una criba significativa que limita la selección de las ocurrencias a contextos de inicio de turno y enunciado, lo que primordialmente me interesa en estas páginas, aunque, por supuesto, siempre hay que contar con las anomalías, las incoherencias o los criterios heterogéneos que suelen aparecer en corpus electrónicos como el que se maneja en esta ocasión. No obstante, en los casos en que el rastreo de las fórmulas se hace asequible por no presentar un número excesivo de ocurrencias (lo que no es el caso, por ejemplo, de Antes como correlativo del latín Imo), también he tenido en cuenta los casos en que estas aparecen en principio de turno no absoluto, sino después de un marcador, otra fórmula o un segmento topicalizado previo. Por ejemplo, en el caso de la fórmula Yo os lo diré también he considerado como válidas para el propósito que me mueve en estas páginas las ocurrencias del tipo Eso yo te/os lo diré, Por mi fe que yo telos lo diré, vocativo + yo telos lo diré o verbo en imperativo + que yo telos lo diré, donde, evidentemente, el pronombre no aparece en el corpus electrónico con la primera letra en mayúscula.
} 
enunciador. En ocasiones, tal fórmula antecede a un monólogo antes del cual el interlocutor es interpelado por el otro dialogante con la intención de que desarrolle más por extenso la idea que acaba de aducir o la anécdota que ha presentado. Así se puede comprobar en los siguientes ejemplos de los Coloquios de Erasmo:

(1) Eu: Plane venatio est: sed aliud venor, quam apros aut cervos 'Claro que es caza, pero cazo cosas distintas a jabalíes y ciervos'.

Ti: Quid igitur? '¿Qué entonces?'

Eu: Dicam. In uno pago [...] 'Te lo diré. En un campo [...]' [Convivium religiosum $]^{7}$.

(2) Lu: Atqui inde solent redire deteriores. Quo pacto tibi diversum accidit? 'Pero de aquí suelen salir peores. ¿Cómo te pasó a ti de otra manera?'

So: Dicam: quia non eodem animo modoque Romam adii 'Te lo diré: porque no fui a Roma con el mismo espíritu ni del mismo modo' [Adolescentis et scorti].

En las traducciones de los Coloquios que nos han llegado este Dicam es traducido por los segmentos discursivos Yo te/(v)os lo diré o Dezirtelo hel Dezir(v)oslo he, con sus diversas variantes gráficas y, en el último caso, también morfológicas. La razón por la que en latín no aparecen los pronombres, tanto el tónico como los átonos, está relacionada con el problema de la marcación de la polaridad: en latín, Dicam no necesita otras marcas explícitas de la polaridad o la asertividad ${ }^{8}$, pero el castellano sí. Se trata de esquemas marcativos que han ido cambiando a lo largo del tiempo y que no han sido todavía satisfactoriamente estudiados ${ }^{9}$. A continuación presento dos ejemplos extraídos del Uxor mempsigamos y del Pietas Puerilis:

(3) $\mathrm{X}$ : Sed narra nobis, obsecro, quibus artibus pertraxeris maritum ad tuos mores.

E: Dicam in hoc, vt imiteris [Um, lín. 107-109, p. 304].

- X: Pues cuentame por amor de mi: con que artes traxiste atu marido atus costumbres.

E: Dezirtelo he: para que tu hagas como yo [Bat. 474, lín. 9-11, f. a4v].

\footnotetext{
${ }^{7}$ Los ejemplos latinos provenientes de obras diferentes a las que conforman el corpus de este estudio (cfr. infra CORPUS) se extraen del portal DERCF.

${ }^{8}$ El concepto de polaridad proviene de las teorías generativas. González Rodríguez (2008: 1) explica este fenómeno como "la sensibilidad que presentan algunas unidades léxicas a ciertos contextos [...], en [el sentido de] que algunos elementos no pueden aparecer libremente en cualquier entorno".

${ }^{9}$ Cfr., sin embargo, algunas aportaciones en este ámbito de Hernanz y Batllori (2009), Dufter y Octavio de Toledo (2014) y Rodríguez Molina (2014).
} 
- X: Pues cuenta me por amor de mi con que arte traxiste a tu marido a tus costumbres.

E: Dezir te lo he para que tu hagas como yo [Bat. 479, lín. 23-26, f. CVIIIr] - X: Dime ruegote con que artes pudiste hazer tu marido a tus costumbres? O: Dezir te lo he para que procures delo hazer assi [Bat. 478, lín. 9-11, f. g5r].

(4) E: Dic istud explanatius, nam non satis assequor quid velis.

G: Dicam. Finge recitari Epistolam [Pp, lín. 1678-1679, p. 176].

- E: Di esso mas claramente porque no entiendo bien lo que quieresdezir.

G: Dezir te lo he:finge que se reza la epistola [Bat. 479, lín. 17-19, f. XIIr].

- E: Declarame esso que no lo entiendo bien.

G: yo te lo dire. Pon que se diga la epistola [Bat. 478, lín. 28-1, f. e7r-e7v].

A través de la búsqueda realizada en el CORDE he constatado que existe un total de 422 coincidencias para Yo te lo diré con sus variantes gráficas y morfológicas más importantes, de las cuales 229 (54,3\% del total) se documentan en el período comprendido entre 1520 y 1700 (SO). Para formas que integran pronombres enclíticos del tipo Decirtelo he y semejantes el resultado obtenido es de $14(63,6 \%)$ ocurrencias en el período de mayor influencia erasmiana sobre un total de 22. Aunque, como se advirtió que consideraría relevante en términos cuantitativos, el número de ocurrencias en el período $\mathrm{SO}$ es superior a la mitad de las ocurrencias totales computadas de la fórmula, el hecho de que $154(36,5 \%)$ se localicen en la época ASO me hace dudar de que esta fórmula sea especialmente típica del discurso dialógico renacentista y barroco. En todo caso, pese a que se dé también en el período ASO, nada impide pensar que se haya asimilado con bastante naturalidad en la época SO. Por supuesto, no se podrá negar que se trata de un segmento prototípico, eso sí, del discurso dialógico en cualquier época e incluso apto como fórmula conversacional, con similares efectos discursivo-argumentativos, incluso en contextos familiares en la actualidad. Sea como fuere, baste este par de ejemplos de SO para evidenciar la rentabilidad de esta fórmula en el diálogo renacentista:

(5) Mercurio: No hará, porque los franceses \& ingleses ha ya muchos días que tienen auisados sus mercaderes, y bástales aquel término para retirar sus mercaderías, lo que no haze a los súbditos del Emperador, porque no están auisados ni lo podrían en tan breue tiempo hazer.

Carón: Esso no entiendo yo.

Mercurio: Yo te lo diré. Como los franceses \& ingleses sabían a qué tiempo el Emperador [Alfonso de Valdés, 1528, Diálogo de Mercurio y Carón].

(6) Luis: ¿No nos diríades qué son los delitos que cometen y cómo los hazen, pues que generalmente tanto mal dezís dellos?

Antonio: Dezíroslo he, pero no particularmente porque sería ymposible acabar de contar sus maldades y trayciones [Antonio de Torquemada, 1553, Coloquios satíricos]. 


\section{Dicam > Yo te lo diré}

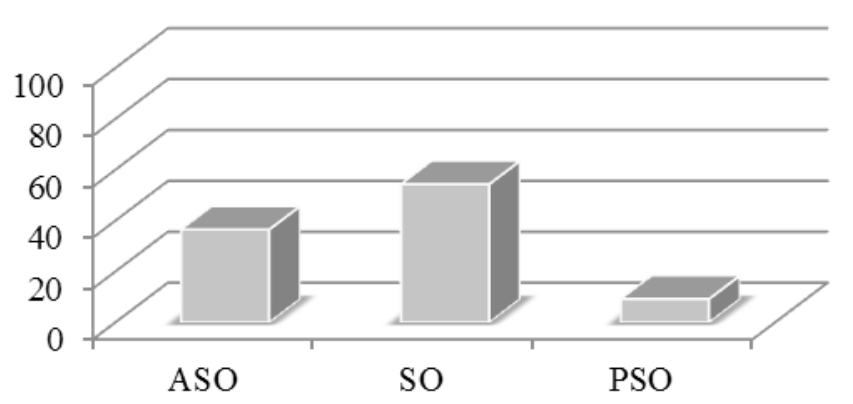

GRÁFICO 1.—Estadísticas de Yo te lo diré y variantes por épocas en CORDE

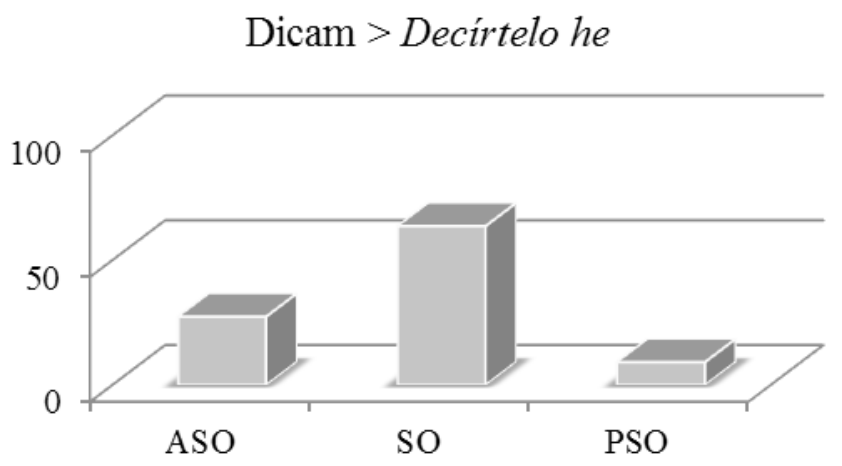

GRÁFICO 2.-Estadísticas de Decírtelo he y variantes por épocas en CORDE

2.2. Como expresión de sorpresa, y en determinados contextos también de rechazo ante la afirmación previa, los personajes de los Coloquios emplean con bastante frecuencia la expresión interrogativa Quid (ego) audio? ${ }^{10}$ Se trata en este caso de un verbo de percepción física común en el diálogo en tanto que favorece la ficción conversacional recreando el canal comunicativo en el que se desarrolla el supuesto intercambio oral:

(7) Le: Sed iamne peperit uxor? ¿Pero ya dio a luz la mujer?'

Ae: Iamdudum, et quidem gemellos 'Ya hace tiempo, y, además, gemelos'.

Le: Quid ego audio? ‘Qué oigo?’ [Concio sive Merdarus]

\footnotetext{
${ }^{10}$ Se estudia esta fórmula más detenidamente desde una perspectiva diacrónica en del Rey (en 2015b).
} 
(8) Ch: Ita est, sed deficit nos materia 'Así es, pero nos faltó madera'.

Al: Quid audio? Nihil illic silvarum? ‘Qué oigo? ¿No había allí bosque?' [Charon]

La traducción más frecuente en los Coloquios es la fórmula ¿Qué es lo que oigo?, con sus variantes gráficas (9 y 10). Los primeros ejemplos similares que se encuentran son los de la Celestina (11), donde la expresión incluye un demostrativo anafórico. La forma más simple y parecida al segmento que acopia Erasmo es ¿Qué oigo? En ASO solo se contabilizan 6 ejemplos $(5,9 \%)$ de cualquiera de los tipos que acabo de mencionar, mientras que del período SO se documentan $32(31,7 \%)$. El total, cuando no se introduce ninguna limitación cronológica en el buscador de CORDE, es de 101 ocurrencias, es decir, más del doble de la cifra que constituyen los resultados para SO. Ello nos habla de una presencia considerable de esta fórmula durante el Renacimiento y el Barroco, pero también de un avance importante de esta durante los siglos posteriores. Es decir, se trata de un segmento propio del discurso dialógico quizá revitalizado por la prosa de raigambre erasmiana pero que se prodiga con más intensidad en el diálogo de la novela realista (12) y en el Romanticismo - llamativo es el reiterativo uso que de él hace, por ejemplo, la comedia de esta época, como la de Larra (13)—:

(9) X: Semel duntaxat eo incaluerat vtrinque contentio, vt minimum res abfuerit a pugna.

E: Quid ego audio? [Um, lín. 42-44, p. 302]

- X: Una tan sola vez anduuo la question tan trauada de ambas partes: que poco falto de darnos puñadas.

E: Que es lo que oyo? [Bat. 474, lín. 9-11, f. a3v]

- X: Una tansola vez anduuo la quistion tan trauada de ambas partes : que poco falto de venir alas puñadas.

E: Que es lo que oyo? [Bat. 479, lín. 13-15, f. CVIv]

- X: Una vez me acuerdo que nos encendimos entramos de manera que ayna anduuieramos a malas.

O: O que donayre tan grande ${ }^{11}$ [Bat. 478, lín. 26-1, f. g3r-g3v].

- E: V na sola vez anduuo la quistion de tal modo:que poco faltopara venir alas puñadas.

D: Que es lo queoygo [Luj, lín. 10-11, f. E3v].

(10) G: Nunquam, sed crebro sollicitatus sum a quibusdam ab hoc seculo, velut a naufragio, ad portum monasteriorum [F, Q: vocantibus].

E: Quid ego audio? Captabant praedam? [Pp, lín. 1779-1781, p. 179]

11 Aquí Virués sustituye la fórmula interrogativa por una expresión exclamativa de sorpresa con similar intención comunicativa. 
- G: Nunca:pero muchas vezesfue[sic]amonestado de algunos que dezian que mesaliesse del siglo assi como denaufragio o pielago peligroso y me fuesse al puerto queson los monesterios.

E: Que eslo que oyo? querian asirte? [Bat. 479, lín. 17-22, f. XVv]

- G: Nunca, pero muchas vezes he sido persuadido de algunos frayles a que dexada la tempestad deste siglo me recogiesse enel puerto de algun monesterio.

E: Que oyo?Caçar te querian [Bat. 478, lín. 4-8, f. f4r]

(11) Celestina: Y óyeme, que en pocas palabras te lo diré, que soy corta de razón. A Melibea dejo a tu servicio.

Calisto: ¿Qué es esto que oigo?

Celestina: Que es más tuya que de sí mesma; más está a tu mandado y querer que de su padre Pleberio [Fernando de Rojas, 1499, la Celestina].

(12) - ¡Ah! Te ha embriagado el amor, el amor hacia Ángela.

$-¡$ Ah!

- Maldita sea.

- ¿Qué oigo?

Y Eduardo sacó un puñal [Emilio Castelar, 1862, La hermana caridad].

(13) Conde: Pues señor, no me conocerá usted tal vez ya; sin embargo, yo soy de Barcelona, me llamo Bernardo Pujavante.

Bernardo: ¿Qué oigo? ¿usted Bernardo Pujavante? [Mariano José de Larra, 1831, No más mostrador]

\section{Quid (ego) audio? > ¿Qué (es lo que) oigo?}

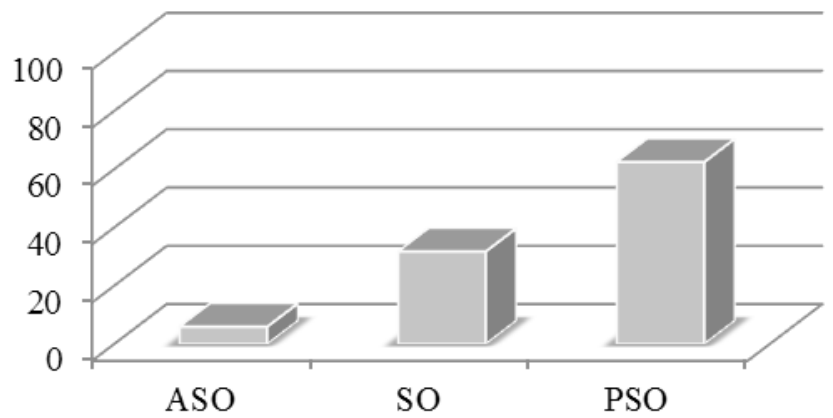

GRÁFICO 3.-Estadísticas de ¿Qué (es lo que) oigo? y variantes por épocas en CORDE

2.3. Con el objetivo de mantener el clima de cortesía verbal y fomentar los movimientos cooperativos en el diálogo, Erasmo introduce en sus Coloqiuos la 
fórmula de asentimiento y aceptación de la intervención previa Verum (est) o Vera narras/praedicas. Es en esta última donde se hace explícito el verbo de lengua que se revela como una preferencia de traducción en el caso de la mayoría de los intérpretes. Ejemplos de los Colloquia son los siguientes:

(14) Le: Atqui solet hoc genus mire deditum esse isti sodalitio 'Pero esa clase [de personas] suele ser incré́blemente devota a este tipo de congregaciones'.

Hi: Vera praedicas, sed coeperunt et foeminae sapere 'Dices verdad, pero comenzaron a tener sabiduría también las mujeres' [Concio sive Merdarus].

(15) $\mathrm{Ph}$ : Turpius est lucrum ex mendacio, quam ex lotio 'Más fea es la ganancia que se obtiene de la mentira que la de los desechos'.

Ps: Verum est, inquam; sed iis, qui mentiendi nesciunt artem 'Cierto, lo afirmo, pero para los que ignoran el arte de la mentira' [Pseudochei et Philetymi].

Efectivamente, los traductores se decantan por la traducción Dices la verdad con diversas variantes: dices/dizes la verdad, verdad dices/dizes, etc.:

(16) E: Idem ius erit tibi apud me. Hoc certe postulat nostra necessitudo, ab ipsis pene incunabulis inter nos inita.

$\mathrm{X}$ : Vera narras, nec vlla sodalium vnquam carior fuit animo meo [Um, lín. 76-78, p. 303].

- E: La mesma ternas tu: para dezirme lo que quisieres: porque assi sin dubda lo requiere la amistad: que siempre desde nuestra niñez auemos tenido.

$X$ : Dizes la verdad: y nunca yo tuue amiga a quien tanto como ati quisiesse [Bat. 474, lín. 5-9, f. a4r] [Bat. 479, lín. 2-7, f. CVIIv].

- O: Lo mesmo podras tu hazer comigo pues lo requiere assi la amistad que entre nosotras desde nuestra niñez siempre vuo.

X: Assi es la verdad que nunca amiga tanto quise como a ti [Bat. 478, lín. $11-15$, f. g4r].

- D: La misma tendras tu ,para dezirmelo que te paresciere, que assilo requiere el amistad ,que dende nuestra niñez nos tuuimos.

E: Dizes la verdad que nunca tuue amiga a quientanto quisiesse como ati [Luj, lín. 14-19, f. E5r].

(17) G: Scis enim similitudine morum conglutinari familiaritatem ac beneuolentiam.

E: Verum, sed non inter competitores eiusdem magistratus, quum simili laborent morbo [Pp, lín. 1824-1827, p. 181].

- G: porque como sabes lasemejança delas costumbresayumta y añuda el amistad y beniuolencia.

E: Uerdad dizes:pero essa amistad no se ayunta entrelos que procuran y compiten sobrealguna dignidad quando ambosjuntamente trabajan y se congoxan por la alcançar [Bat. 479, lín. 15-21, f. XVIIr]. 
- G: Ca la semejança delas costumbres confedera mas la familiaridad y bien querencia.

E: Uerdad es ${ }^{12}$ mas esso no a lugar entre los que competen sobre alguna dinidad: aunque son semejantes enla dolencia [Bat. 478, lín. 13-17, f. f5r].

De acuerdo con los datos del CORDE que he recopilado, esta fórmula de asentimiento o aceptación discursiva es bastante frecuente en el discurso dialógico de SO. 122 ocurrencias de las 178 documentadas en todas las épocas se dan en este período, lo que supone un porcentaje considerable $(68,5 \%)$. Se trata de un segmento, además, permeable a la variación en inicio de turno. Así, encontramos ejemplos como Dizes muy gran verdad, varias veces documentado en Alfonso de Valdés (18); Tú dizes gran/la verdad (19), o Dices/Dizes, vocativo, verdad (20), sobre todo en la comedia, probablemente por razones métricas ${ }^{13}$ :

(18) Carón: No es cosa nueua que los romanos pontífices se muestren ingratos a los que son causa de ponerlos en aquella dignidad.

Mercurio: Dizes muy gran verdad, y aun es muy bien empleado que acaezca esso a los que tienen más respecto a sus propósitos e interesse particular que al seruicio de dios y bien vniuersal en la creación del supremo pastor de la yglesia [Alfonso de Valdés, Diálogo de Mercurios y Carón, 1528].

(19) Miçilo: Y ansí es neçesario que cuanto más libres sois [los eclesiásticos] seáis más perversos, y ya cuando os subjetáis a alguno dezís que ha de ser al Pontífiçe solo, y a éste queréis por juez porque está muy lexos y muy ocupado, y cometiendo la causa vos eligeréis juez que no os haya de matar.

Gallo: Tú dizes la verdad. Pero, ¿qué quieres que se haga en tales tiempos como éstos en que estamos, que si alguno el día de hoy es sufrido, manso y bueno todos se le atreven? [Cristóbal de Villalón, ca. 1555, Crótalon]

(20) Auté: Apunta, o a punto ponte,

porque parece de guerra,

y un hombre solo y armado

suele ser como un nublado

que la tempestad encierra.

Dulcanquellín: Dices, amigo, verdad:

a verle en alto te sube;

que el que no temió la nube

padeció la tempestad [Lope de Vega, 1596-1603, El Nuevo Mundo descubierto por Cristóbal Colón].

${ }^{12}$ En este caso Virués realiza una traducción quizá más literal, reponiendo solo el verbo copulativo. También en (16) emplea la tercera persona del verbo ser que sustituye al verbo de lengua del texto fuente al que precede un adverbio modal. En efecto, Verdad es y semejantes son también un inicio de turno conversacional típico del discurso dialógico, pero cuya adscripción temporal es más amplia y no mayoritaria en el período SO.

${ }^{13}$ En la prosa, como puede advertirse en el ejemplo (21), se prefiere colocar el vocativo tras la fórmula, sin intercalar. 
Aunque constituye una fórmula ya empleada en ASO, época en la que se computan hasta 31 ejemplos $(17,4 \%)$, sin duda su desarrollo está ligado a la tradición discursiva propiamente dialógica que eclosiona en SO. Verdad dices, por ejemplo, es un inicio de turno conversacional todavía muy querido por Cervantes (21), aunque tras 1700 esta fórmula ${ }^{14}$ entra en decadencia - solo he documentado 25 casos $(14,1 \%)$ para PSO—. Según he podido colegir de las traducciones de los Coloquios, la variante Así es la verdad (cfr. n. 12), con o sin el artículo, es igualmente frecuente en SO como inicio absoluto de turno conversacional. De hecho, 279 (80,9\%) de las 345 ocurrencias datan de esta época. Cervantes, de nuevo, la emplea profusamente en los diálogos del Quijote (22). Se trata esta última, por lo demás, de una fórmula de asentimiento con poca presencia en los diálogos de ASO, como revela el escaso porcentaje de las estadísticas que presento más abajo (cfr. gráfico 4). En PSO se computa solo el 16,8\% de los ejemplos de Así es (la) verdad, por lo que, aunque todavía podemos encontrarlos en la novela realista y costumbrista (23), puede afirmarse que esta fórmula es característica de la tradición discursiva dialógica de $\mathrm{SO}$ :

(21) Mas, ¡ay del alma desdichada que se vee puesta en términos de acordarse del bien perdido, y con temor del mal que está por venir, sin que vea ni halle remedio ni medio alguno para estorbar la desventura que le está amenazando, pues tanto más fatigan los dolores cuanto más se temen!

Verdad dices, hermosa Galatea - dijo Damón-, que no hay duda sino que el repentino y no esperado dolor que viene no fatiga tanto, aunque sobresalta, como el que con largo discurso de tiempo amenaza y quita todos los caminos de remediarse [Miguel de Cervantes, 1585, La Galatea].

(22) Yo apostaré que este buen hombre que viene consigo es un tal Sancho Panza, su escudero, a cuyas gracias no hay ningunas que se le igualen.

- Así es la verdad — dijo Sancho-, que yo soy ese gracioso y ese escudero que vuestra merced dice, y este señor es mi amo, el mismo don Quijote de la Mancha historiado y referido [Miguel de Cervantes, 1605-1615, el Quijote].

(23) - Ya que por vuestro mandato he de parlar canto llano, vos diré, señora, que esta merced que de vos recibo la acojo con más gratitud de vuestra pudicia, cuanto hasta ahora no vos merecí que crueldades y sofrenadas.

- Así es la verdad, caballero; más parad mientes que las doncellas treintenas, como yo, han de esquivarse con más ansia que los arrapiezos de quince a veinte; materia feble e quebradiza e que vos enloquecen a vosotros los amadores [Serafín Estébanez Calderón, 1847, Escenas andaluzas, bizarrías de la tierra, alardes de toros, rasgos populares, cuadros de costumbres...].

\footnotetext{
${ }^{14}$ Entiéndase, con la mayoría de sus variantes sintagmáticas y ortográficas.
} 


\section{Verum (est)-Vera narras/praedicas > Verdad dices/Dices verdad}

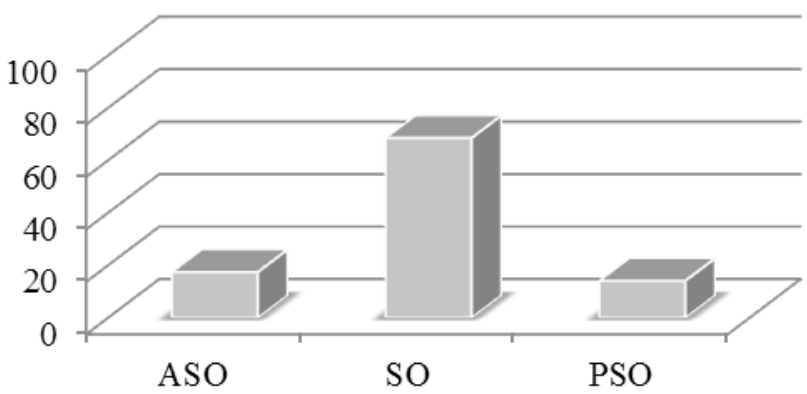

GRÁFICO 4.-Estadísticas de Verdad dices y variantes por épocas en CORDE

\section{Verum (est)-Vera narras/praedicas > Así es(la) verdad}

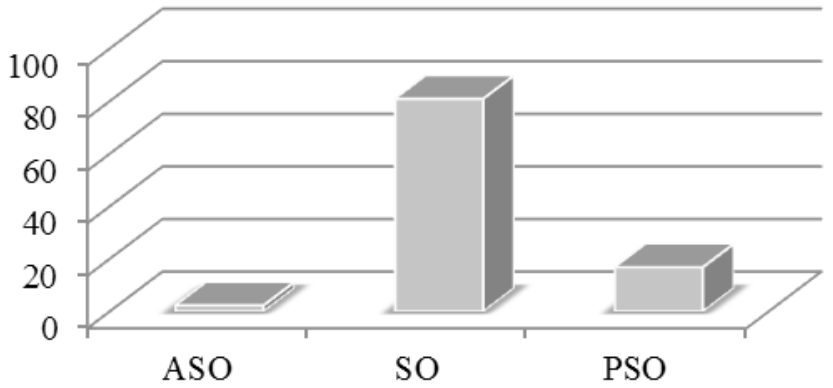

GRÁFICO 5. Estadísticas de Así es (la) verdad y variantes por épocas en CORDE

2.4. De casi idéntico significado pragmático es el inicio de turno Bien dices/ dizes o Dices/Dizes bien, que en las traducciones de los Coloquios corresponde a la frecuente fórmula erasmiana de aceptación dialógica Recte dicis/(ad)mones:

(24) Ca: At iam tempus est, ut ex animante bruto in hominem incipias verti 'Pero ya es hora de que de animal sin razón empieces a convertirte en hombre'.

Po: Recte mones. Nam horum temporum prophetae dicunt instare supremum mundi diem 'Bien me aconsejas, pues los profetas de hoy dicen que se acerca el final de los días' [Cyclops sive Evangeliophorus]. 
(25) Pe: Sellam igitur una cum pulvino mihi poni iube 'Manda, pues, ponerme una silla con cojín'.

Ch: Recte admones; nam sedens commodius mentieris 'Bien dices, pues sentado harás el simulacro más cómodamente’ [Formulae].

En las traducciones de los Coloquios, se halla la traducción de la fórmula de Erasmo mediante la anteposición del adverbio intensificador muy (26), segmento absolutamente recurrente en el inicio de turno conversacional en los diferentes diálogos del período SO (27), al igual que la del pronombre exclamativo qué (28) o el personal tónico (29), como refuerzo de la deixis externa:

(26) E: sunt sua cuique vitia: quae si vsquam, certe in matrimonio nouisse oportet, non odisse.

X: Recte mones [Um, lín. 96-98, p. 304].

- E: cada vno tiene sus vicios: que sien cualquier otra conuersacion se requiere: mayormente enel matrimonio conuiene: que se conozcan: mas no que se aborrescan.

X: Muy bien dizes [Bat. 474, lín. 28-31, f. a4r].

- E: cada vno tiene sus vicios: lo qual si en alguna parte conuiene ser conocido y no aborrecido: es sin duda principalmente enel matrimonio.

X: Muy bien dizes [Bat. 479, lín. 4-8, f. CVIIIr].

- E: ninguno ay sin tacha: el remedio delas quales mas esta en conocellas que en aborrecellas: y esto principalmente a lugar enel matrimonio.

X: Muy bien lo dizes ${ }^{15}$ [Bat. 478, lín. 13-17, f. g4v].

- D: cada vno tiene sus vicios. Lo qual si en alguna parte,conuiene ser conoscido:es entre los casados.

E: Muy bien dizes [Luj, lín. 12-14, f. E6r].

(27) Berganza: y, finalmente, cómo les pintaban la fealdad y horror de los vicios y les dibujaban la hermosura de las virtudes, para que, aborrecidos ellos y amadas ellas, consiguiesen el fin para que fueron criados.

Cipión: Muy bien dices, Berganza; porque yo he oído decir desa bendita gente que para repúblicos del mundo no los hay tan prudentes en todo él, y para guiadores y adalides del camino del cielo, pocos les llegan [Miguel de Cervantes, 1613, El coloquio de los perros].

(28) Marcela: ¿Acabáis de concertar

este enredillo los dos?

¿Qué pesar que puede hacer,

que está el cuitado temblando?

Riselo: Qué bien dices, confirmando

que ya no debes de ser

mi fuego, pues tiemblo a ti;

que si a ti me calentara,

claro está que no temblara [Lope de Vega, 1608, El acero de Madrid].

15 De nuevo es Virués quien más dúctil se muestra a la hora de variar las fórmulas erasmianas, en este caso intercalando en ella un pronombre átono de objeto directo. 
(29) Vayan de aquí fuera los demonios que quisieren estorbar tan sabroso nudo, y no procuren los hombres apartar lo que Dios junta.

- Tú dices bien, señor Andrea — replicó Isabela-; y, sin que aquí intervengan trazas, máquinas ni embelecos, dame esa mano de esposo y recíbeme por tuya [Miguel de Cervantes, 1616, Los trabajos de Persiles y Segismunda].

En total he contabilizado 526 ocurrencias de Bien dices y sus variantes en el CORDE, de las cuales 348, esto es, más del $66 \%$ del global, pertenecen a SO, mientras que apenas el 3\% (14 ocurrencias) se corresponden con la época ASO. Podría ser significativo el hecho de que las fórmulas con el adverbio antepuesto, como en latín, revelen una absoluta mayoría en la época SO, mientras que Dices bien y dices bien ofrecen más ejemplos en PSO — lo que no ocurre, claro, con Dizes bien y dizes bien, por la cuestión ortográfica-, pues ello podría estar relacionado con una mayor presencia del modelo propiamente erasmiano en la construcción de los diálogos. En PSO es notable el uso de este segmento conversacional inicial en la novela realista (30), los diálogos de Larra o el teatro del XVIII y el XIX (31):

(30) Yo no sé; no tienen idea de la economía. Si hubiera estado a mis órdenes, ya habría andado derecho — dijo D. ${ }^{a}$ Romualda.

- Dices bien, Romualdita: lo que este muchacho ha hecho no tiene nombre [Benito Pérez Galdós, 1872, Rosalía].

(31) Rita: Voy a traer luces. Procuraré detenerme por allá abajo hasta que vuelvan... Veré lo que dice y qué piensa hacer, porque hallándonos todos aquí, pudiera haber una de Satanás entre la madre, la hija, el novio y el amante; y si no ensayamos bien esta contradanza, nos hemos de perder en ella.

Doña Francisca: Dices bien... Pero no; él tiene resolución y talento, y sabrá determinar lo más conveniente... ¿Y cómo has de avisarme?... Mira que así que llegue le quiero ver [Leandro Fernández de Moratín, 1805, El sí de las niñas].

\section{Recte dicis/(ad)mones > Bien dices-Dices bien}

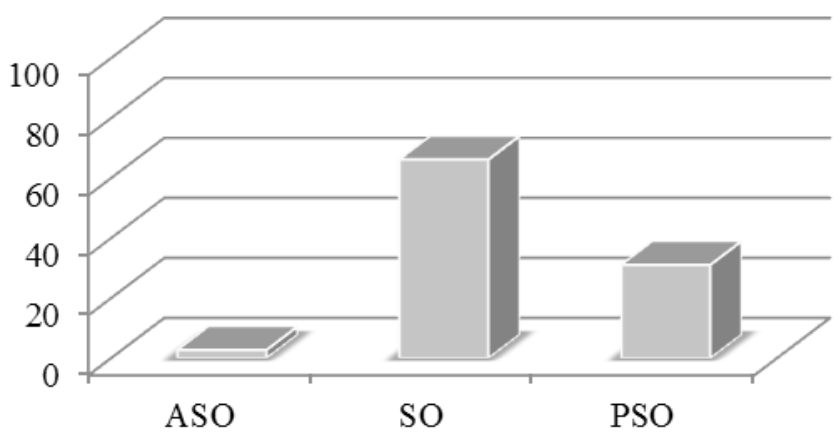

GRÁFICO 6.-Estadísticas de Bien dices y variantes por épocas en CORDE 
2.5. Otra fórmula de inicio de turno conversacional recurrente en los Colloquia es Bona verba. Mediante ella se reprende al interlocutor por una afirmación previa que el receptor considera inaceptable o por el uso de ciertos vocablos considerados inadecuados. Se trata de un enunciado metalocutivo de reacción que expresa, pues, el desacuerdo del interlocutor sin que se vea dañado el "contexto acomodaticio" (Haverkate, 1998: 180-181) favorable a la cortesía verbal:

(32) Ma: An igitur vis, ut posthac abs te deflectam noxios oculos? '¿Acaso quieres que después aparte de ti mis ojos culpables?'

Pa: Bona verba. Imo magis afflecte 'Habla bien. Más bien vuélvelos hacia mí' [Proci et Puellae].

(33) Le: Quid eo? ¿¿Por qué [mandaste a tu hijo] allí [a París]?'

Ae: Ut Magister nobis redeat stultior, quam exierat 'Para que regresara a nosotros un profesor más tonto de lo que se había ido'.

Le: Bona verba 'Habla bien' [Domestica confabulatio]

En las traducciones se opta por un enunciado directivo que integra un verbo de percepción y uno de lengua: Mira(d) (bien) lo que dices/dizes/decís/dezís. Por supuesto el primero debe entenderse en sentido figurado y guarda relación con el valor recriminativo que se asocia con frecuencia al imperativo del verbo mirar:

(34) X: Superi male faxint, qui ius hoc nobis ademerunt.

E: Bona verba. Sic visum est Christo [Um, lín. 83-84, p. 303].

- X: Mal haga dios alos que tal derecho nos quitaron.

E: Que buennas [sic] palabras ${ }^{16}$. Assi le parescio a Christo que se deuia hazer [Bat. 474, lín. 14-16, f. a4r].

- X: Mal haga dios alos que tal derecho nos quitaron.

E: Mira lo que dizes:cata que assi lo ordeno christo [Bat. 479, lín. 14-16, f. CVIIv].

- X: Malle haga dios aquien essa ley reuoco.

O: Mira lo que dizes que lo establecio assi jesu christo [Bat. 478, lín. 21-22,

f. g4r].

- E: No se que mouio a quien tal derecho nos quito.

D: Christo lo quito ${ }^{17}$ [Luj, lín. 8-10, f. E5v].

(35) $\mathrm{X}$ : [Dotem prodigit q]uibus ipsi visum fuerit; vino, scortis, alea.

E: Bona verba.

\footnotetext{
${ }^{16}$ Morejón ofrece una traducción literal con enunciado exclamativo que su enmendador corrige de manera radical. Es posible que Morejón desconociera el significado pragmático de la fórmula erasmiana, pues yerra sistemáticamente cuando se enfrenta a este segmento — cfr. también (35)-

${ }^{17}$ Luján ha variado la sintaxis del texto de manera que no se conserva la fórmula en su versión.
} 
X: Atqui sic res habet [Um, lín. 29-31, p. 302].

- X: [Gasta la dote e]nlas [cosas] que ael le paresce. en beuer: en putas: en juegos.

E: Buena cosa.

X: assi es como te digo [Bat. 474, lín. 30-32, f. a3r].

- X: [Gasta la dote e]nlo que ael le paresce : en beuer, con putas y tambien en juegos.

E: Mira lo que dizes!

E: Assi es como te digo! [Bat. 479, lín. 22-24, f. CVIr]

- X: [Gasta la dote e]n lo que a el se le antoja: en vino y mugeres y juegos.

O: Mira lo que dizes que es esso cosa rezia.

X: Es laverdad como yo lo digo [Bat. 478, lín. 12-15, f. g3r].

- E: Ha lo [el dote] quarteado sin auer hecho delictoporque lo merezca [...].

El vn quarto a putas:el otro a naypes: el otro a vino,y el otro alcaguetas [...].

D: Mira bien lo que dizes, tiempla tu enojo,no digas cosa de que quiça despues te arrepientas [...].

E: Assi es como te digo [Luj, lín. 17-7, f. E2v-E3r].

El resultado global para esta fórmula es de 48 ocurrencias, de las cuales 30 $(62,5 \%)$ pertenecen al período $\mathrm{SO}(36,37$ y 38$)$ y ninguna a $\mathrm{ASO}$, por lo que no puede hablarse de tradición autóctona previa en este sentido. Tal vez se trate de uno de los casos más probables de influencia de las traducciones castellanas de los Colloquia sobre el discurso dialógico posterior:

(36) Mili: Aunque no quedasse con nosotros quedariamos bien seguros, que no nos lo lleuas tu contigo.

Cli: Mira lo que dizes Milicio, que no me suenan bien esas palabras.

Mili: Bien cayo, en lo que quieres dezir: y no tienes en este caso de que reprehenderme: por que aunque hable de Dios, como comunmente aca solemos tratar las cosas terrestres, que lleuandolas vno no pueden quedar en lugar, donde las tomo [Diego Núñez Alba, 1552, Diálogos de la vida del soldado].

(37) Palatino: Entretanto, encomendémonos a Dios y a la buena gente deste lugar, que si no nos acogen de grado, por fuerza mal recado tenemos, según lo tienen bien cercado.

Pinciano: Mirá lo que decís, que no es lugar, sino villa, y la más leal del reino [Juan de Arce de Otárola, 1550, Coloquios de Palatino y Pinciano].

(38) Artillero: Muchos años ha que tiro plaça y en diversas occasiones me he hallado a servirla.

General: Mirad bien lo que dezís, hermano, porque yo os prometo que havéys llegado a parte a pedirla donde os harán bien sudar el copete [Luis Collado, 1592, Plática manual de artillería]. 


\section{Bona verba > Mira (bien) lo que dices}

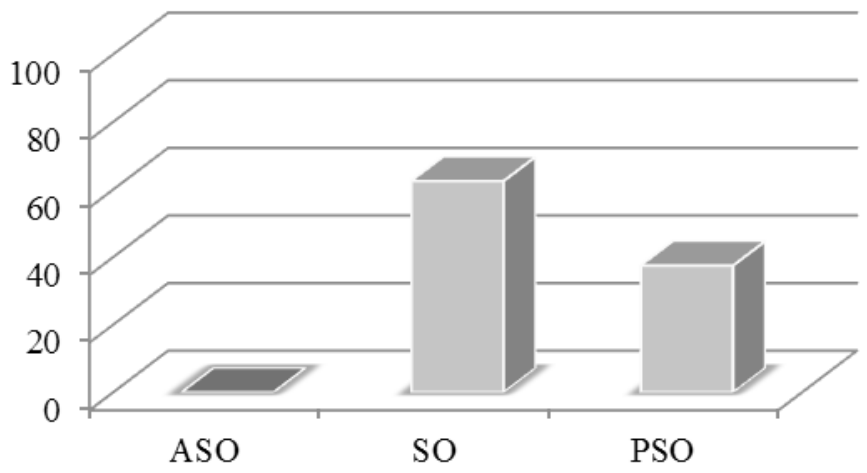

GRÁFICO 7.-Estadísticas de Mira (bien) lo que dices y variantes por épocas en CORDE

2.6. Determinadas fórmulas conversacionales en Erasmo son características de los personajes más "pasivos" de los Coloquios, es decir, los que asumen, ya sea a lo largo de todo el diálogo ya en una parte determinada de él, el papel de receptor y se mantienen como realidades dialógicas que sostienen la ficción conversacional, en numerosas ocasiones interviniendo solo para romper pasajes monológicos más o menos extensos. Una de ellas es la expresión de sorpresa y/ o interés Qui sic o Quid ita, mediante las que se interroga acerca de la causa del enunciado o de la enunciación previos, de ahí que el siguiente turno conversacional esté iniciado frecuentemente por la conjunción causal Quia o un enunciado justificativo en el mismo turno que expresa la disconformidad con la intervención precedente:

(39) Pe: Sed tu mihi videre cochleae vitam agere 'Pero me parece que vives como un caracol'.

Io: Qui sic? ‘'Por qué?'

Pe: Quia perpetuo domi lates, nec vsquam prorepis 'Porque siempre andas escondido en casa y nunca sales' [Domestica confabulatio, apud ASD: 139].

(40) Aug: Vtinam isthuc verbi tacuisses, hilariores surrexissemus a coena. Miseros nos reddis ante tempus 'Ojalá no hubieses dicho eso: nos habríamos levantado más contentos de la cena. Nos haces más desgraciados antes de tiempo'. Ch: Quid ita? Minus anguem odi, quam pisces '¿Por qué? Menos odio le tengo a la serpiente que a los peces' [Convivium profanum, apud ASD: 207].

Pese a que los traductores podrían haberse decantado por otro tipo de interrogativas de carácter causal del tipo ¿Por qué (lo dices)? y semejantes, como en alguna ocasión (41) se observa que hacen, la mayoría de ellos se decanta por 
la traducción más literal, tal como se aprecia en los ejemplos extraídos del Senile (41) y del Uxor mempsigamos (42):

(41) G: Non totum hoc fortunae debeo, ne quid erres.

Po: Qui sic?

G: Dicam, alii prius diligunt, quam deligant [Sen, lín. 82-84, p. 377].

- G: No te yerres: que no deuo todo esto ala fortuna.

Po: como assi.

G: Dezir telo he:otros amanprimero que escogen [Bat. 479, lín. 13-15, f. XIXv].

- G: Mira hermano no te engañes pensando que a caso me sucedio tanbien.

Po: Porque lo dizes?

G: yo telo dire. Otros ay que escogen muger mas por afficion que por elecion [Bat. 478, lín. 28-3, f. x3v-x4r].

(42) $\mathrm{X}$ : At ego vellem me nupsisse fungo, quum meo nuberem Nicolao.

E: Quid ita, quaeso te? tam cito male conuenit inter vos? [Um, lín. 15-17, p. 377].

- X: Mas yo mas quisiera auerme casado con vn hongo: quando me case con mi Nicolao

E: Como assi, por tu vida? tan presto ha nascido tan mala auenencia entre vosotros? [Bat. 474, lín. 15-18, f. a3r]

- X: No como yo que mas quisiera auer me casado con vu [sic] hongo: quando me case con mi Nicolao.

E: Como assi por tu vida:tan presto estays desauenidos? [Bat. 479, lín. 24-4, f. CVIr]

- X: ami tanto mevaliera casar convn hongo quando conel mio case.

O: Que es esso $^{18}$ hermana/tan presto ha nacido descontentamiento entrevosotros? [Bat. 478, lín. 21-24, f. g2v]

- E: Bien puedes llamarte dichosa, no como yo,que mas quisiera auerme casado con vn negro de Guinea:quando me case con mi marido. O quando por mejor dezir me enterraron, o estarme como me estaua sola.

D: Como y tan presto estays desauenidos. Tan presto ay discordias entre vosotros [Luj, lín. 11-19, f. E1v]

Teniendo en cuenta todas las variantes ortográficas de esta fórmula y descartando inicios de turno conversacional con enlace conjuntivo del tipo Como así lo vio u otros que integran un adverbio así con función modal dependiente de un verbo explícito en el enunciado del tipo ¿Cómo así me insultas?, he contabilizado 273 ocurrencias de ¿Cómo así? en el CORDE. Solo 10 de ellas $(3,6 \%)$ se dan en el período ASO, más de 5 en el siglo XVI, mientras que 169 (aproximadamente el 61,9\%) pertenecen a obras de la época SO:

18 De nuevo Virués se aleja de las soluciones más formulaicas de los otros traductores. También, en parte, Luján en la siguiente traducción, pues se decanta por la expresión de sorpresa con eliminación del adverbio modal. 
(43) Lu: ¡En el ánima me has tocado, maestro!

Pas: ¿Cómo assí?

Lu: Diez y seis años ha que me cativaron los moros una hija de dos años viniendo de Sicilia a esta ciudad, que jamás he sabido d'ella ninguna cosa [Juan de Timoneda, 1559, Comedia llamada Cornelia].

(44) Policronio: Aquí vamos nosotros; no temáis que os capeen.

Filaletes: La mesma capa es capeadora.

Policronio: ¿Cómo ansí?

Filaletes: Ya sabéis por Plinio que, si se revuelven las plumas de las otras aves con las de las águilas, se hallan en pocos días roídas dellas [Juan de Pineda, 1589, Diálogos familiares de la agricultura cristiana].

En este sentido, creo que esta fórmula puede considerarse un elemento característico de la tradición dialógica de SO que sigue teniendo vigencia en PSO. De hecho, es la fórmula de las tratadas en este artículo que con más insistencia aparece en los datos que el CORDE ofrece para el siglo XX (45). Habría que rastrear más detenidamente hasta cuándo este segmento sigue dándose en la literatura peninsular y por qué se trata de una fórmula que, según parece, sigue teniendo vigencia en el español americano incluso en contextos de inmediatez comunicativa, es decir, no solo en la literatura culta:

(45) - No, no voy con ustedes; tengo la camioneta para mí.

- ¿Cómo así? - preguntó Santiago.

Lester no entendía la conversación de los hermanos [Alfredo Bryce Echenique, 1970, Un mundo para Julius].

\section{Qui sic?-Quid ita? > ¿Cómo a(n)sí?}

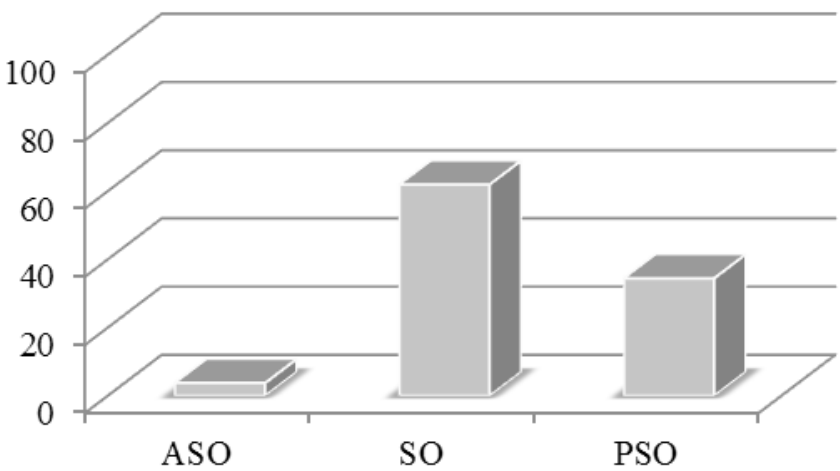

GRÁFICO 8.-Estadísticas de ¿Cómo $a(n)$ sí? y variantes por épocas en CORDE 
2.7. Como enunciado introductorio de un comentario valorativo por parte del personaje, es común en los Coloquios de Erasmo el verbo (Non/Haud/Nec) Miror/Demiror, con el que o se demuestra el asombro ante las palabras del interlocutor o se minimiza, mediante la negación del verbo, la importancia de estas, que quizá buscaban una reacción diferente por parte del enunciador:

(46) Po: Hoc gestum est coram aliquot testibus 'Esto pasó en presencia de algunos testigos'.

Ca: Miror hominem non fuisse protinus exanimatum. Sed ut pergamus: vivis caste? 'Me sorprendo de que ese hombre no cayera de repente desmayado. Pero continuemos: ¿vives castamente?' [Cyclops sive Evangeliophorus]

(47) Le: Quid interim agitur domi tuae? ‘QQué se hace entretanto en tu casa?' Ae: Multa sane, quae nolim 'Ciertamente, muchas cosas que no me gustan'. Le: Non miror. Sed iamne peperit uxor? 'No me extraña. ¿Pero dio a luz ya tu mujer?' [Domestica confabulatio]

En las distintas versiones de los Coloquios encontramos como reflejo en romance de la fórmula latina las estructuras verbales Maravíllome/Me maravillo y Espántome/Me espanto, con posibles variantes ortográficas:

(48) G: Circumspiciebam, quid cuique succederet, quid secus.

Po: Miror tibi tantum fuisse mentis, quum Lutetiae nihil fuerit te nugacius [Sen, lín. 65-67, p. 377].

- G: andaua mirando lo quebien o mal sucedia a cada vno.

Po: Marauillo me quetuuiste tanto seso porque en paris no auia cosamas burlona y perdida quetu [Bat. 479, lín. 21-24, f. XIXr].

- G: Andaua examinando y ponderando los daños y prouechos que de cada cosa se suelen seguir.

Po: Espanto me que touiste tanto seso:que me acuerdo yo que eras en Paris vn perdido [Bat. 478, lín. 7-11, f. x3v].

(49) E: Equidem haud miror, gallinacee, si parum pinguisti, quodque tantum senii tibi collegeris [Sen, lín. 232-233, p. 382].

- E: En verdad gallinazo:que agora no me marauillo si engordastepoco:y cogistetanta vejez [Bat. 479, lín. 24-26, f. XXIIIv].

- E: En verdad que no me espanto ahora de verte tan magro:ni de verte tan presto tan viejo [Bat. 478, lín. 26-28, f. x8r].

Tenidas en cuenta todas estas fórmulas ${ }^{19}$, de la primera de ellas el CORDE ofrece 200 ocurrencias, de las cuales $130(65 \%)$ se dan en la época SO, con

${ }^{19}$ He descartado los ejemplos del CORDE con minúscula que no se localizan en lo que podríamos considerar la primera parte del turno conversacional, es decir, solo he tenido en cuenta los casos de maravíllome, espántome y maravillado estoy, con sus variantes, que aparecen tras un vocativo, un pronombre sujeto, un adverbio intensificador o un operador modal. 
intensa presencia en los diálogos de Valdés (50), Villalón (51) y Arce de Otárola (52):

(50) Arcidiano: Creo que decís muy gran verdad.

Latancio: Maravíllome que, viendo muerto al Capitán general, no desmayaron (como comúnmente suele acaecer) y dejaron el combate [Alfonso de Valdés, 1529, Diálogo de las cosas acaecidas en Roma].

(51) Miçilo: Calla; si no en verdad que te dé con esta horma en la cabeça, que más provecho me harás en la olla cuando amanezca, que hazes ahí vozeando.

Gallo: Maravíllome de tu ingratitud, Miçilo, pues a mí que tanto provecho te hago en despertarte por ser ya hora conveniente al trabajo, con tanta cólera me maldizes y blasfemas [Cristóbal de Villalón, ca. 1555, Crótalon].

(52) Pinciano: No la cobdiciéis desas, que cuestan muy caras y los que las traen suelen ser cobdiciosos y avarientos, porque de costarles caras cuando mozos, vienen cuando viejos a guardar bien la renta quia pretium sanguinis est.

Palatino: No me maravillo que lo guarden, que, a la verdad, no lo ganan holgando, sino sirviendo a Dios y al Rey por mar y por tierra y poniendo la vida al tablero mil veces [Juan de Arce de Otárola, 1550, Coloquio de Palatino y Pinciano].

Un porcentaje considerable (32\%, 64 ocurrencias), sin embargo, representa el período anterior (ASO), lo que habla de una reutilización de la fórmula en el diálogo renacentista que va decayendo a partir de 1700. Es interesante que la mayoría de ocurrencias de Maravíllome y similares en ASO se dé en el diálogo de la novela de caballerías (53), con el propósito de destacar los sucesos imprevistos, la novedad de las aventuras y otros acontecimientos narrativos que comentan y ponderan los personajes:

(53) El Rey los miró de mal semblante, y díxoles:

- Mucho me maravillo de lo que me dezís que yo dexe en vos mi tierra y mi casa, que yo con todos los que en ello pongo no es remedio para ello, iy vosotros, en quien no veo tanta discreción, pensar de lo cumplir! [Garci Rodríguez de Montalvo, 1482-1492, Amadís de Gaula]

En el diálogo renacentista, sin embargo, esta fórmula tiene una función discursiva bien distinta, pues se relaciona más directamente con los movimientos argumentativos que se suceden en el diálogo. Abundante también en la novela de caballería es la variante Maravillado/a soy/estoy (54), pero igualmente en la Celestina (55) y en los diálogos de SO (56 y 57), período en que se computan $33(56,8 \%)$ de las 58 ocurrencias para Maravillado/a soy/estoy: 
(54) El Emperador, cuando se lo dixo, fízole fazer muy rica sepultura y fizo venir a los dos cavalleros de Validos ante él y díxoles:

- Amigos, muy maravillado soy del Rey de Boemia consentir a su fijo que con tal demanda viniese, que yo por amigo lo tengo [1512, Primaleón].

(55) Centurio: Tenla, por Dios, señora, tenla; no se te suelte.

Elicia: Maravillada estoy, prima, de tu buen seso. ¿Cuál hombre hay tan loco y fuera de razón que no huelgue de ser visitado, mayormente de mujeres? [Fernando de Rojas, 1499, la Celestina]

(56) Debiendo un mercader gran cuantidad de moneda a infinitos creedores, vínole a visitar cierto amigo suyo por la mañana, y, como fuese muy tarde y le hallase en la cama, díjole:

- Maravillado estoy, señor, cómo podéis dormir, debiendo tanto.

Respondió:

- Más os habéis de maravillar de cómo pueden dormir tantos [Juan de Timoneda, 1564, Buen aviso y portacuentos].

(57) - ¿Hay más [partidas], hijo? —dijo Monipodio.

- Sí, otra — respondió Rinconete-, que dice así:

"Al sastre corcovado que por mal nombre se llama el Silguero, seis palos de mayor cuantía, a pedimiento de la dama que dejó la gargantilla. Secutor, el Desmochado".

- Maravillado estoy — dijo Monipodio- cómo todavía está esa partida en ser [Miguel de Cervantes, 1613, Rinconete y Cortadillo].

En el caso de Espántome y sus variantes, la preponderancia de empleo en SO es más evidente aún, pues casi el 90\% (34 ocurrencias) del total se corresponde con esta época:

(58) Mercader: Pues en esta caxa verá vuestra merced el primor del mundo: todo es obra de Milán.

Tomás: Obra de Milán, veeme y no me tangas.

Margarita: Nada de esto me contenta.

Mercader: Espántome cómo se casó vuestra merced, siendo tan mal contentadiza [1599, Diálogos de John Minsheu].

(59) Maravillóse no poco el prior de oýr lo que el novicio le dezía, y, lleno de suspensión, le respondió diziendo:

- Espántome, monsiur de Japelín, de vuestra indiscreción y que tan poco os ayan aprovechado los exercicios espirituales, en que en diez meses de religioso avéys tratado, y los buenos consejos míos que, como padre, os he siempre dado [Alonso Fernández de Avellaneda, 1614, Don Quijote de la Mancha]. 
(Non/Nec) Miror/Demiror > Maravillome/Me maravillo

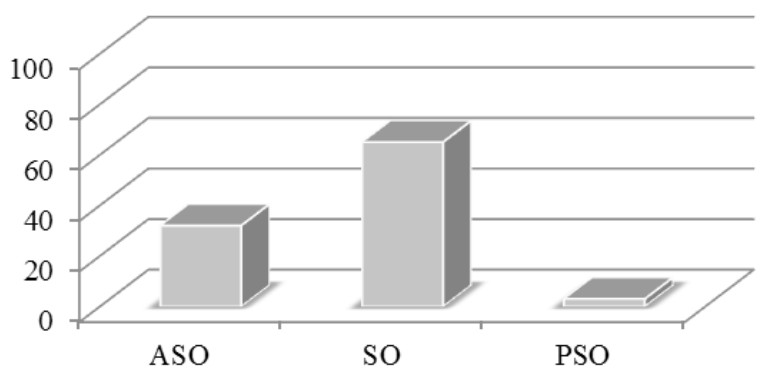

GRÁFICO 9.-Estadísticas de Maravíllome y variantes por épocas en CORDE

(Non/Nec) Miror/Demiror > Maravillado/a estoy/soy

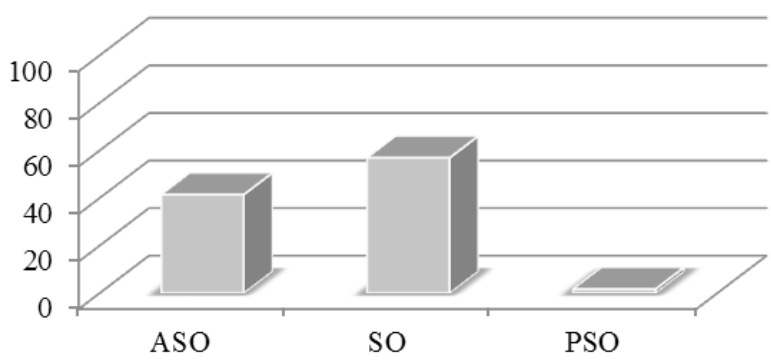

GRÁFICO 10.-Estadísticas de Maravillado estoy y variantes por épocas en CORDE

(Non/Nec) Miror/Demiror > Espántome/Me espanto

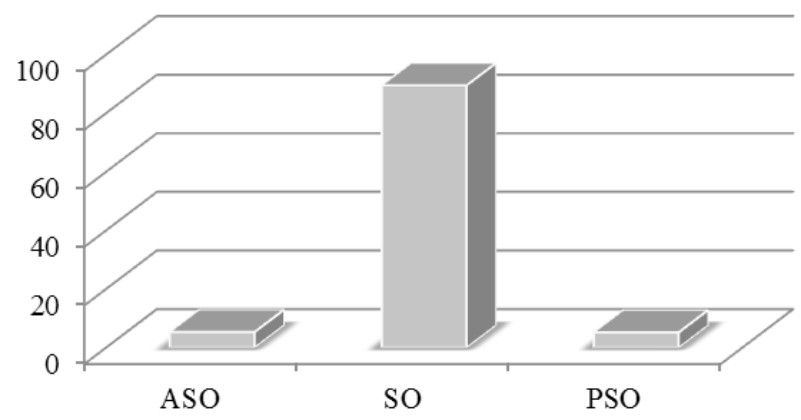

GRÁFICO 11.-Estadísticas de Espántome y variantes por épocas en CORDE 
2.8. Frecuentes son, en diferentes partes de la intervención de los personajes, los operadores discursivos conversacionales construidos con la palabra $f e$. También a principio de turno Erasmo suele utilizar el marcador bona fide precedido del verbo dico en imperativo y el dativo de primera persona para solicitar del interlocutor sinceridad en la respuesta a la interrogativa, directa o indirecta, que dicho marcador suele introducir (60) o para destacar asombro sobre la veracidad de la afirmación previa (61), en cuyo caso el marcador constituye en sí un enunciado interrogativo independiente:

(60) Aug: Hoc aenigma tibi coniectandum relinquo: ego Sphingem praestiti, tu Oedipus esto 'Te dejo este enigma para que conjetures: yo haré de esfinge y tú serás Edipo'.

Ch: Dic mihi bona fide, Augustine; nulla tibi cum Gallis unquam fuit necessitudo? 'Dime sinceramente, Augustino: ¿nunca tuviste afinidad con los franceses?' [Convivium profanum]

(61) Ga: Id si feceris, cedam tibi huius certaminis palmam 'Si lo haces te daré la victoria sobre esta batalla'.

Er: Bona fide? ‘¿De verdad?'

Ga: Optima 'No hay nada más verdadero' [Lusus pueriles].

Las traducciones de los Coloquios suelen combinar, como ocurre en latín, el operador al principio de la intervención con un verbo de lengua:

(62) E: Dic nobis bona fide, qui nullum vitae genus non expertus es, quod omnium maxime probas? [Sen, lín. 401-402, p. 386]

- E: Di nospor tu fe pues que ningunlinaje de vida dexaste de experimentar qual te paresce mejor? [Bat. 479, lín. 3-4, f. XXVIIIr]

- E: Dinos aqui por tu fe laverdad sin passion ni temor/pues has esperimentado todas las maneras de biuir qual te parece la mejor [Bat. 478, lín. 27-2, f. y4v-y5r].

En general, en SO es frecuente también el uso de esta fórmula marcativa generalmente acompañando a un vocativo y casi siempre a un verbo de decir (63), aunque el enunciado directivo puede expresarse con modalidad distinta de la imperativa:

(63) Filonio: Si por tu parte no la ha avido, por la suya avía tantas que vasten para quitarla de culpa quanto a ti te parecerá tenerla mayor por ellas.

Torcato: Por tu fe, Filonio, que tú me las digas, pues yo no las alcanço ni entiendo [Antonio de Torquemada, 1553, Coloquios satíricos].

También, como en Erasmo, existen ejemplos donde por tu fe constituye pregunta que representa un turno conversacional completo:

(64) Vidriano: ¡O, cómo me has consolado! 
Dios te dexe hazer buen fin.

Secreto: Oripesta se a asomado

a la rexa del jardín.

Vidriano: ¿Por tu fe?

Secreto: Cierto a mí paréceme [Jaime de Huete, 1535, Comedia Vidriana].

Un 69,4\% (109 ocurrencias) del total se localiza en SO, período tras el cual el marcador tiende a desaparecer, según las estadísticas del CORDE. Sí es significativo el número de ocurrencias en ASO, 41 (26,1\%), lo que podría explicar que en SO se tome este marcador como traducción, no literal, del bona fide erasmiano.

\section{Bona fide $>$ Por tufe}

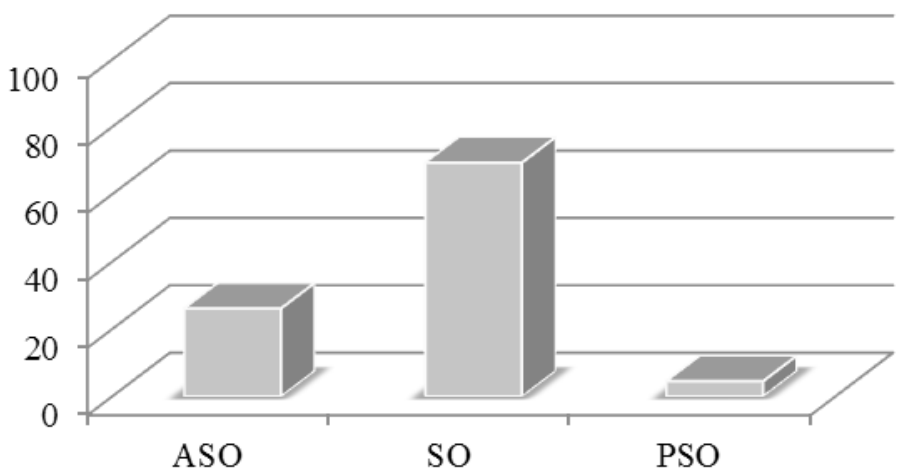

GrÁFICO 11.-Estadísticas de Por tu fe y variantes por épocas en CORDE

2.9. Otro marcador abundantísimo a principio de turno o de enunciado es Imo, que introduce una expresión adversativa, ya sea en contradicción con el enunciado mismo del interlocutor (65) ya con la presuposición derivada de sus palabras (66). Sea como sea, siempre introduce un segmento de mayor valor en la escala argumentativa con respecto al segmento discursivo al que se enfrenta. Como inicio absoluto de turno es ampliamente utilizado en los Colloquia, pero también como inicio de enunciado tras un breve comentario de la intervención anterior del personaje, pues imo en contexto dialógico no puede distar mucho del movimiento enunciativo con el que se contrapone en virtud de su naturaleza polifónica:

(65) E: In quo mari occurrit iste scopulus, aut quod habet nomen? ¿¿En qué mar se encuentra ese escollo o qué nombre tiene?'

Pa: Mare non possum dicere, sed scopulus plurimorum infamis exitiis, Latine dicitur alea; quomodo vos Graeci nominatis nescio 'El mar no lo puedo de- 
cir, pero el escollo, famoso por la desgracia de muchos, se llama en latín "alea ‘juego"”. Cómo lo llamáis los griegos lo ignoro'.

E: O te stultum! '¡Oh insensato de ti!'

Pa: Imo stultior pater, qui tantam summam crederet adolescenti 'Más insensato fue mi padre, que dio una fortuna tan grande a un muchacho' [Sen, lín. 265-269, p. 383].

(66) E: Tu nobis trimestris foetus iocum renouas? ¿Me estás intentando hacer creer el chiste del parto en tres meses?'

$\mathrm{X}$ : Nequaquam 'En absoluto'.

E: Ita necesse est, si tempus a nuptiarum die supputas 'Ha de ser eso, si echas cuentas desde el día de la boda'.

$\mathrm{X}$ : Imo ante nuptias fuerat mihi cum eo colloquium 'Es que antes de la boda ya tuve conversación con él' [Um, lín. 349-352, p. 311].

Una de las traducciones más extendidas de este marcador, a veces omitido en las versiones, es el conector adversativo antes:

(67) Po: Reliquit orbum?

G: Imo superest quadriga liberorum, filii duo, filiae totidem [Sen, lín. 87-88, p. 378].

- Po: Dexote algunhuerfano

G: Antesme dexo vnquadro hehijos [sic] dos varones y doshembras [Bat. 479, lín. 18-20, f. XIXv].

- Po: Quedaste sin hijos?

G: Antes quede con dos hijos y dos hijas [Bat. 478, lín. 8-9, f. x4r].

Puesto que la búsqueda de este marcador podría ofrecer resultados inabarcables en la base de datos, para el análisis cuantitativo he limitado la búsqueda a los casos de Antes — con mayúscula- en concurrencia con diferentes pronombres demostrativos ${ }^{20}$, pues este conector adversativo se relaciona con mucha frecuencia, anafórica o catafóricamente, con estos elementos ${ }^{21}$. Tras eliminar los ejemplos de antes delque y de antes como adverbio temporal, creo que los resultados son, también en este caso, reveladores. Aunque en el monólogo es un conector con bastante uso durante toda la Edad Media, a principio de turno dialógico solo he contabilizado 7 ocurrencias $(5,4 \%)$ a lo largo de ASO en el CORDE. En cambio, en SO el porcentaje se eleva hasta el 76,9\% (100 ocurren-

\footnotetext{
${ }^{20}$ No obstante, para los ejemplos aducidos en este apartado, también he tenido en cuenta los resultados de Antes, con mayúscula, a lo largo de todo el período $\mathrm{SO}$, de los que extraigo preferentemente aquellos en los que Antes aparece en principio absoluto de turno.

${ }^{21}$ Las búsquedas realizadas han sido del tipo Antes dist/4 esto, eso y variantes. Una búsqueda así delimitada ofrece ejemplos con el demostrativo antepuesto al conector hasta un máximo de cuatro palabras previas y pospuesto hasta un máximo de cuatro palabras posteriores. Ello es útil para localizar ejemplos de antes en relación anafórica y catafórica con respecto al demostrativo, aunque con mucho la catáfora está más representada.
} 
cias de un total de 130). En PSO el uso de este conector entra en decadencia. Son muchos los ejemplos de Antes como inicio de turno tanto en las partes dialogadas de obras narrativas como en el teatro de Lope de Rueda (68) y, por supuesto, en los diálogos de SO (69 y 70):

(68) Leno: ¿Qué's hoy?

Troyco: Jueves.

Leno: ¿Jueves? ¿Quánto le falta para ser martes?

Troyco: Antes le sobran dos días [Lope de Rueda, Pasos].

(69) Mercurio: Ea, pues, no te fatigues Carón, que no te buscara yo sino para quitarte deste cuydado.

Carón: ¿Búrlaste?

Mercurio: Antes lo digo de verdad, y hasme tú hecho andar perdido por acá y por acullá, buscándote [Alfonso de Valdés, 1528, Diálogo de Mercurio y Carón].

(70) M: Agora lo veréis. Aurelio, daca lo que as escrito. Veis aquí anotado todo lo que avéis dicho, y yo tengo por tal al escrivano que ha sabido bien lo que ha escrito.

V: Con la bendición de Dios, yo huelgo dello, pero con tanto que lo tengáis para vosotros y no lo traigáis de mano en mano, porque ya veis el inconveniente.

M: Antes porque veo el provecho, y no el inconveniente, pienso darlo a todos los que lo querrán, y aun, si me pareciere, lo haré imprimir [Juan de Valdés, ca. 1535, Diálogo de la lengua].

La novedad, como indica Cano Aguilar (2007: 22), es que a partir del siglo XVI la aparición del adversativo antes no exige la presencia de un enunciado negativo previo, sino que puede limitarse a indicar justamente lo contrario de lo que se ha dicho o a matizar y/o rechazar parte o la totalidad de la intervención que motiva el enunciado que tiende a vencer en el enfrentamiento dialécticoargumentativo, es decir, precisamente el introducido por Imo/Antes. Tal vez esta novedad esté relacionada con la revitalización del conector como traducción de imo en contextos dialógicos como los de los Colloquia erasmianos:

(71) E: Religiosior tu quidem es, quam pro aetate.

G: Imo nullam aetatem non decet religio [Pp, lín. 1515-1516, p. 172].

- E: Masreligioso eres que lo pidetu hedad.

G: Antes a toda hedad conuiene la religion [Bat. 479, lín. 23-3, f. VIIr-VIIv]. - E: Mas deuoto y religioso me parece que eres delo que se suele hallar en otros de tu edad.

G: Antes me parece ami que ninguna edad ay enque no conuenga al hombre biuir religiosamente [Bat. 478, lín. 27-2, f. e2r-e2v]. 
(72) Carrión: Y con estos pedreros, ¿siempre se tira bala de piedra?

Artillero: Antes, señor, con estos pocas vezes se tira bala [Luis Collado, 1592, Plática manual de artillería].

(73) Silvestre: Dejemos cumplimientos proprios de cortessanos oçiossos, que suelen gastar con ellos el tiempo infructuosamente; y por que no haga yo el efecto del agua de por sant Juan, os suplico que boluais a buestra platica, que mi voluntad y desseo merecen que participe della.

Boscán: Antes holgare que la mudemos, por que entiendo que no os a de ser agradable por ser lo que tratauamos de la Caça, cossa, a lo que ymagino, agena de buestro gusto [Luis Barahona de Soto, 1580-1600, Diálogos de la montería].

\section{Imo $>$ Antes... [demostrativo]}

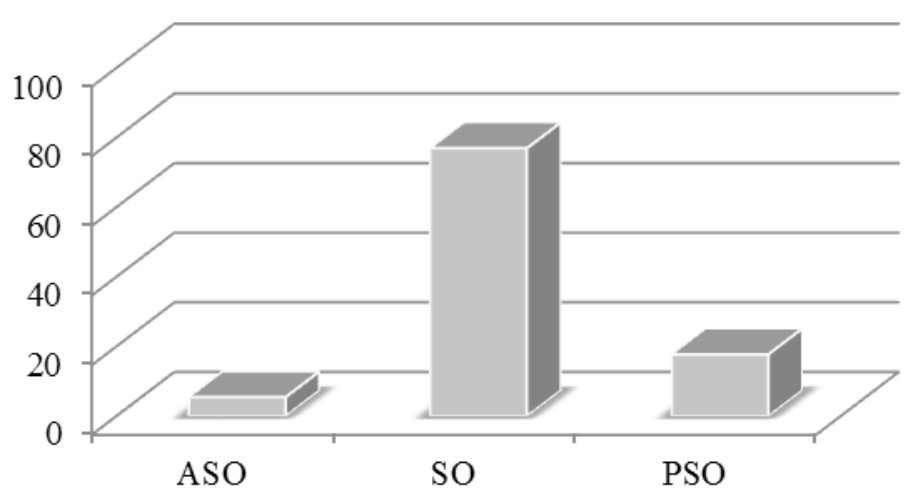

GRÁFICO 12.-Estadísticas de Antes... [demostrativo] por épocas en CORDE

\section{A MANERA DE RECOPILACIÓN}

A continuación presento un cuadro recopilatorio en el que se reflejan los diferentes resultados obtenidos en CORDE de las diversas fórmulas que he estudiado en las páginas precedentes. Las columnas verticales están divididas en tres tonos distintos que se corresponden con los diversos períodos que he considerado: ASO (hasta 1519), SO (1520-1700) y PSO (1701-1975). Las líneas horizontales representan el porcentaje alcanzado por la fórmula en cuestión en cada época. El predominio del tono de mayor intensidad, correspondiente a SO, salvo en la fórmula Quid (ego) audio > ¿Qué (es lo que) oigo/oyo?, evidencia cómo, en general, tales fórmulas son características de la tradición discursiva dialógica y guardan una estrecha relación, como he procurado demostrar, con segmentos conversacionales de inicio de turno muy frecuentes en los Colloquia de Erasmo: 
Fórmulas de inicio conversacional típicas del discurso dialógico

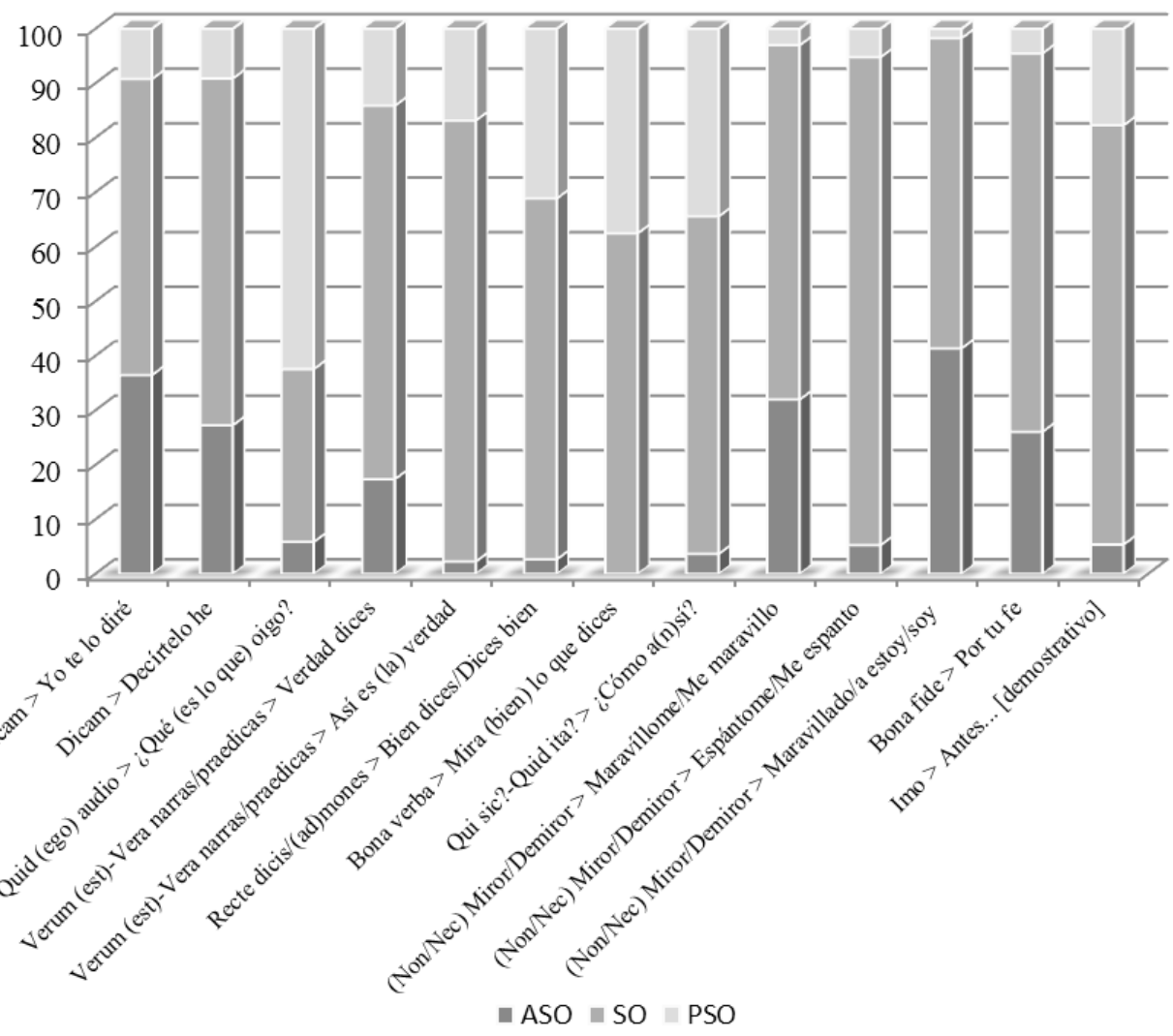

GRÁFICO 13.-Estadísticas de aparición de diversas fórmulas conversacionales por épocas según los datos del CORDE

Análisis de este tipo ayudarán a conocer mejor la configuración discursiva del diálogo renacentista y la de sus herederos textuales, tradición estudiada ampliamente desde una perspectiva histórico-literaria pero carente de una descripción histórico-lingüística satisfactoria, aun cuando se trata de un período del idioma fundamental para la comprensión del entramado variacional de la lengua de la época, en la encrucijada de viejas influencias medievales y nuevas tendencias que prefiguran el español moderno. 


\section{CORPUS $^{22}$}

[Bat. 47423]: Colloquio de Erasmo intitulado Institucion del matrimonio christiano: traduzido de latin en lengua castellana por Diego Morejon, 21 de abril de 1528 (ejemplar carente de los folios 8 y 9, conservado en la Bayerische Staatsbibliothek de Múnich).

[Bat. 475]: Colloquio de Erasmo llamado Mempsigamos, 1528 (versión anónima que enmienda la de Morejón, conservada en la Universidad de Gante).

[Bat. 478]: Colloquios familiares, 1529 (se trata de una colección de 11 coloquios, entre ellos el Pietas puerilis y el Uxor mempsigamos, traducciones de Virués, y el colloquium Senile, traducción anónima. Este volumen se encuentra en la Biblioteca de la Universidad de Valencia, y se puede consultar en la red: <http://trobes.uv.es/>).

[Bat. 479]: Los coloquios de Erasmo, Sevilla (Juan Cromberger), 28 de septiembre de 1529 (colección de 11 coloquios, el Pietas Puerilis y el Senile provenientes de una traducción anónima previa [Bat. 477] y el Uxor mempsigamos en copia del traductor anónimo de Morejón [Bat. 475], volumen conservado en la Biblioteca Nacional de Francia).

[Luj]: Coloquios matrimoniales, Pedro de Luján (1550). Impreso en Sevilla por Dominico de Robertis. La traducción correspondiente al Uxor mempsigamos se encuentra en el segundo coloquio de la obra. Volumen conservado en la Biblioteca Nacional de Madrid.

\section{BIBLIOGRAFÍA}

Alvar, Carlos (1990): "Notas para el estudio de las traducciones italianas en Castilla durante el siglo XV", Anuario Medieval, 2, pp. 23-41.

Aschenberg, Heidi (2003): "Diskurstraditionen: Orientierungen und Fragestellungen", en Heidi Aschenberg y Raymund Wilhelm (eds.), Romanische Sprachgeschichte und Diskurstraditionen. Akten der gleichnamigen Sektion des XXVII. Deutschen Romanistentags, Tübingen, Narr, pp. 1-18.

$A S D=$ Halkin, Léon-E., Franz Bierlaire y René Hoven (eds.) (1972): Opera omnia Desiderii Erasmi Roterodami, Ordinis primi tomus tertius: Colloquia, Amsterdam, North-Holland Publishing Company.

Bataillon, Marcel (2007 [1966]): Erasmo y España, Antonio Alatorre (trad.), México, Fondo de Cultura Económica.

Bustos Tovar, José J. de (2007): "La textualización del diálogo en textos españoles de principios del Renacimiento", Rivista di Filologia e Letterature Ispaniche, X, pp. 201-222.

Bustos Tovar, José J. de (2011): "Hablo como escribo", en José Jesús de Bustos Tovar, Rafael Cano Aguilar, Elena Méndez García de Paredes y Araceli López Serena (eds.), Sintaxis y análisis del discurso hablado en español. Homenaje a Antonio Narbona, Sevilla, Secretariado de Publicaciones de la Universidad de Sevilla, pp. 459-477.

Cano Aguilar, Rafael (1991): "Sintaxis oracional y construcción del texto en la prosa española del Siglo de Oro", Philologia Hispalensis, vol. VI, fasc. I, pp. 45-67.

Cano Aguilar, Rafael (2007): "Conectores del discurso en el español del siglo XVI", Lexis, XXXI (1 y 2 ), pp. 5-45.

${ }^{22}$ Traducciones castellanas de los Colloquia de Erasmo.

${ }^{23}$ La numeración se corresponde con la establecida por Bataillon (2007 [1966]: LII-LIII) en su bibliografía. Por lo demás, en los ejemplos hemos utilizado las siguientes abreviaturas correspondientes a los coloquios: $\mathrm{Pp}=$ Pietas puerilis, $\mathrm{Um}=$ Uxor mempsigamos, $\mathrm{Sen}=$ colloquium Senile La versión latina procede de $A S D$. 
CORDE = Real Academia Española: Corpus Diacrónico del Español, <http: www.rae.es $>$.

$D E R C F=$ Desiderius Erasmus Roterodamus, Colloquia familiaria, en Gregory Crane (ed.), The Perseus Digital Library, <http://www.stoa.org/hopper/text.jsp?doc=Stoa:text:2003.02.0006>.

Dufter, Andreas y Álvaro Octavio de Toledo (eds.) (2014): Left sentence peripheries in Spanish: diachronic, variationist and typological perspectives, Amsterdam/Philadelphia, John Benjamins (Linguistik Aktuell/Linguistics Today).

González Rodríguez, Raquel (2008): La polaridad positiva en español, tesis doctoral, Madrid, Universidad Complutense de Madrid.

Kabatek, Johannes (2001): “¿Cómo investigar las tradiciones discursivas medievales? El ejemplo de los textos jurídicos castellanos", en Daniel Jacob y Johannes Kabatek (eds.), Lengua medieval y tradiciones discursivas en la Península Ibérica. Descripción gramatical, pragmática histórica, metodología, Madrid, Vervuert, pp. 97-132.

Kabatek, Johannes (2005): "Tradiciones discursivas y cambio lingüístico”, Lexis: Revista de lingüística y literatura, 29, 2, pp. 151-177.

Koch, Peter (1993): "Pour une typologie conceptionnelle et médiale des plus anciens documents/ monuments des langues romanes", en Maria Selig et alii (eds.), Le passage à l'écrit des langues romanes, Tübingen, Narr, pp. 39-81.

Koch, Peter (1997): "Diskurstraditionen: zu ihrem sprachtheoretischen Status und zu ihrer Dynamik", en Barbara Frank, Thomas Haye y Doris Tophinke (eds.), Gattungen mittelalterlicher Schriftlichkeit, Tübingen, Narr, pp. 43-79.

Koch, Peter y Wulf Oesterreicher (2007 [1990]): Lengua hablada en la Romania: español, francés, italiano, Araceli López Serena (ed.), Madrid, Gredos.

Gauger, Hans-Martin (1996): “"Escrivo como hablo”. Oralidad en lo escrito”, en Thomas Kotschi, Wulf Oesterreicher y Klaus Zimmermann (eds.), El español hablado y la cultura oral en España e Hispanoamérica, Madrid/Frankfurt, Iberoamericana/Vervuert, pp. 341-358.

Gauger, Hans-Martin (2004): "La conciencia lingüística en la Edad de Oro", en Rafael Cano Aguilar (coord.), Historia de la lengua española, Barcelona, Ariel, pp. 681-699.

Haverkate, Henk (1998): "La contextualización discursiva como factor determinante de la realización del acto de habla interrogativo", Diálogos Hispánicos de Amsterdam, 22, pp. 173-210.

Hernanz, M. ${ }^{\mathrm{a}}$ Lluïsa y Montserrat Batllori (2009): "En torno a la polaridad enfática en español y en catalán: un estudio diacrónico y comparativo", en Joan Rafel (ed.), Diachronic Linguistics - Lingüística Diacrónica - Lingüística Diacrònica, Girona, Documenta Universitaria, pp. 319352.

López Grigera, Luisa (1986): "Estela del erasmismo en las teorías de la lengua y del estilo en la España del siglo XVI", en Manuel Revuelta Sañudo y Ciriaco Morón Arroyo (eds.), El erasmismo en España, Santander, Sociedad Menéndez Pelayo, pp. 491-500.

López Serena, Araceli (2007): "Mesa redonda I. Las tradiciones discursivas en la historiografía lingüística y en la historia de la lengua española", en Marta Fernández Alcaide y Araceli López Serena (eds.), 400 años de la lengua del Quijote. Estudios de historiografía e historia de la lengua española. Actas del V Congreso Nacional de la Asociación de Jóvenes Investigadores de Historiografía e Historia de la Lengua Española, Sevilla, Secretariado de Publicaciones de la Universidad de Sevilla, pp. 49-111.

OEDER = P. S. Allen y H. M. Allen (eds.) (1922): Opus epistolarum Desiderii Erasmi Roterodami, t. IV, Oxford, Clarendon Press.

Oesterreicher, Wulf (1996): "Lo hablado en lo escrito. Reflexiones metodológicas y aproximación a una tipología", en Thomas Kotschi, Wulf Oesterreicher y Klaus Zimmermann (eds.), El español hablado y la cultura oral en España e Hispanoamérica, Madrid/Frankfurt, Iberoamericana/Vervuert, pp. 317-340.

Oesterreicher, Wulf (1997): “Zur Fundierung von Diskurstraditionen”, en Barbara Frank, Thomas Haye y Doris Tophinge (eds.), Gattungen mittelalterlicher Schriftlichkeit, Tübingen, Narr, pp. $19-41$. 
Oesterreicher, Wulf (1998): "Textzentrierung und Rekontextualisierung. Zwei Grundprobleme der diachronischen Sprach- und Textforschung", en Christine Ehler y Ursula Schaefer (eds.), Verschriftung und Verschriftlichung. Aspekte des Medienwechsels in verschiedenen Kulturen und Epochen, Tübingen, Narr, pp. 10-39.

Rey Quesada, Santiago del (2015a): "El "latín cotidiano" como referencia estilística en la conformación del discurso dialógico castellano (s. XVI)", en Araceli López Serena, Álvaro Octavio de Toledo y Huerta, Esme Winter-Froemel y Barbara Job, Tradicionalidad discursiva e idiomaticidad en los procesos de cambio lingüístico, Tübingen, Narr, pp. 209-230.

Rey Quesada, Santiago del (2015b): “¿Qué es lo que oigo? Historia de una fórmula conversacional en el diálogo literario castellano", Revista Internacional de Lingüística Iberoamericana, 26, Sección temática "Oraciones hendidas en el mundo hispánico: problemas estructurales y variaciones", pp. 81-100.

Rivarola, José Luis (1998): "El discurso de la variación en el Diálogo de la lengua de Juan de Valdés", en Wulf Oesterreicher, Eva Stoll y Andreas Wesch (eds.), Competencia escrita, tradición discursiva y variedades lingüísticas. Aspectos del español europeo y americano en los siglos XVI y XVII, Tübingen, Narr, pp. 83-108.

Rodríguez Molina, Javier (2014): "Adverbios y locuciones adverbiales de manera", en Concepción Company Company (dir.), Sintaxis histórica de la lengua española. Tercera parte: Adverbios, preposiciones y conjunciones. Relaciones interoracionales, México D. F., UNAM/ FCE, vol. 1, pp. 733-937.

Russell, Peter (1985): Traducciones y traductores en la Península Ibérica (1400-1550), Bellaterra, Servicio de Publicaciones de la Universidad Autónoma de Barcelona.

Schlieben-Lange, Brigitte (1983): Traditionen des Sprechens. Elemente einer pragmatischen Sprachgeschichtsschreibung, Stuttgart, Kohlhammer.

Serés, Guillermo (1997): La traducción en Italia y España durante el siglo XV. La "Ilíada en romance" y su contexto cultural, Salamanca, Universidad de Salamanca.

Tunberg, Terence (2004): "The Latinity of Erasmus and Medieval Latin: Continuities and Discontinuities", The journal of Medieval Latin, 14, pp. 147-170.

Vincis, Valentina y Carla Miotto (2016): "Algunas consideraciones en torno al concepto de tradiciones discursivas", en Chiara Albertin y Santiago del Rey Quesada (coords.), Hispanica Patavina. Estudios de historiografía e historia de la lengua española en homenaje a José Luis Rivarola, Padova, CLEUP, pp. 199-215.

Fecha de recepción: 7 de octubre de 2014

Fecha de aceptación: 11 de febrero de 2015 